\title{
Comparing the effects of online teaching during the COVID-19 pandemic and traditional teaching in Surgical Nursing
}

\section{Taoyun Zheng (D 52165460@qq.com)}

Hubei University of Chinese Medicine https://orcid.org/0000-0003-0371-3914

\section{Xinhong Zhu}

Hubei University of Chinese Medicine

\section{Research article}

Keywords: COVID-19, undergraduate nursing students, online teaching, Surgical Nursing, traditional teaching

Posted Date: November 17th, 2020

DOI: https://doi.org/10.21203/rs.3.rs-108407/v1

License: (c) (i) This work is licensed under a Creative Commons Attribution 4.0 International License. Read Full License 


\section{Abstract}

Background: The coronavirus disease 2019 (COVID-19) pandemic has necessitated a dramatic shift in how nursing faculty and undergraduate nursing students are educated. This study aims to examine the teaching effectiveness of Surgical Nursing using both face-to-face teaching and online teaching in undergraduate nursing education.

Methods: A quantitative approach was adopted. Year-3 undergraduate nursing students were recruited. face-to-face teaching was conducted in semester 1 , and online teaching was conducted in semester 2 during COVID-19 pandemic. Student evaluations were collected at the beginning of semester 1 and the end of semester 1 and semester 2 .

Results: 162 students were recruited in the study. $45.1 \%$ students held neutral attitude towards online course of Surgical Nursing. Students were more likely to prefer unit quizzes online and mind maps as homework, task-driven learning, recording videos and online question and answer as the means of theoretical teaching online, and watching surgical nursing skills video and case-based learning in groups as the means of practical teaching online. However, nearly $62.4 \%$ students admitted the effectiveness of online teaching was worse than face-to-face teaching. During online teaching, the mean grades of student in unit quizzes were improved, but there were no differences in student evaluations of instruction mean scores for critical thinking, self-directed learning and self-efficacy in comparison with the baseline. Additionally, differences between the face-to-face and online teaching were found in terms of self-directed learning, critical thinking and self-efficacy.

Conclusion: The effectiveness of online teaching was not superior to the traditional teaching. Although online teaching has advantages of convenience, speed, anytime and anywhere, face-to-face teaching in classroom and interpersonal interaction in the real situation are insurmountable limitations in online teaching.

\section{Background}

Coronavirus disease 2019 (COVID-19) as public health emergency of international concern, caused by the severe acute respiratory syndrome coronavirus 2 (SARS-CoV-2), was outbreak in Wuhan, China on 31December 2019 that is now global pandemic and has infected 20, 439,814 patients from more than 200 countries by 13 August $2020^{[1]}$. The growing number of infected people and deaths and no cure found against COVID-19 forced nearly all countries to apply restrictions, sanctions, social distancing and self-isolation to block spreading virus, which are leading the suspension of life worldwide. COVID-19 pandemic is challenging all circles of society overworld, especially for education. UNESCO estimated that the closure of educational institutions is affecting 890 million students in 114 countries ${ }^{[2]}$. Universities have either postponed or canceled classroom-based class and academic activities, and modified teaching plans to prevent students and professors from infected as a result of health crises. The impact 
of this lethal COVID-19 will reverberate in global higher education much longer after the pandemic has been finally controlled.

Since February 2020, following the government's requirement of "nonstop teaching and learning" education in China has experienced an unprecedented online teaching practice. In a short time period, millions of faculty members started to teach in front of a computer screen via Tencent Classroom, QQ group, Tencent Meeting, WeChat, ZOOM and Ding Talk app. Online teaching is not a new concept, webbased and technology-integrated learning has been embedded in education for many years. However, the global scale and speed of the current educational disruption are unfortunately unmatched because of COVID-19 outbreak. It is a massive, challenge and disruptive shift to move all the existing courses to online in a matter of days. Meanwhile, shifting from face-to-face to online classes has raised concern about faculty members' capability to deal with existing technology. In general, an elaborate lesson plan, lecture content and course PowerPoint (PPT) as well as technology support teams are required for holistic online course. Nevertheless, most faculty members were lack of experience in online teaching and in the absence of well-considered, durable learning plans. In addition to the challenges to the faculty, evidence has indicated that students were lack of good learning attitudes and self-discipline, and more than $60 \%$ Chinese college students spend more time in-class study than out-class according to their study time ${ }^{[3]}$. At present, universities should hold positive and prudent attitudes towards online teaching, adhere to the educational concepts of "openness", "sharing" and "student-centered" and provide educational technology support and various online educational resources, which promote online teaching in an orderly and effective manner. Besides, the faculty should coordinate the characteristics of online learning and the actual needs of students, and avoid copying the same methods, duration and arrangement of in-class teaching.

Nowadays, COVID-19 pandemic has placed unprecedented demands on medical education, which disrupted medical students' clinical clerkships, in-person classes, lab tests, practical and medical conferences, with most being replaced by recorded lectures or live-streams ${ }^{[4]}$. The benefits of online teaching have been well documented in terms of increased accessibility to education, efficacy, cost effectiveness, learner flexibility and interactivity ${ }^{[5]}$. Admittedly, online teaching has been widely applied in continuing education, undergraduate and graduate education, and patients' guidance ${ }^{[6-9]}$. Therefore, by cancelling in-person classes, many medical students may perceive little change in their study schedule, but the loss of clinical skills training and practical in clinical has the potential to become a detriment to medical education, especially for surgical education. In addition, attending class in-person, real-time feedback and back and forth are hard to replicate in online teaching. Therefore, how to guarantee the effect of medical online teaching during the COVID-19 outbreak is worth to be explored further.

Nursing is a very practical subject, which is required to assure that students have opportunities to practice what they have learned in class and in the clinical setting. Surgical Nursing, as a compulsory and core course of nursing professional course system, is the science of clinical nursing that provides optimal comprehensive care in the field of surgery, which focuses on cultivation of clinical thinking and clinical practical skill. Therefore, the transition face-to-face learning to online teaching may be particularly 
challenging to those in the Surgical Nursing as many conventional Surgical Nursing education pedagogies rely on "hands-on" practical experience. This study aimed at evaluating the teaching effectiveness of online teaching vs face-to-face learning in Surgical Nursing among undergraduate nursing students and sharing experiences of Surgical Nursing educators in changing their teaching practice during the COVID-19 pandemic.

\section{Method}

\section{Design}

A single-group, three-time point repeated measures design in this study.

\section{Participants}

Participants were enrolled from a convenience sample comprising third-year nursing students at School of Nursing, Hubei University of Chinese Medicine. The criteria for involvement in the research was being voluntary to participate in the study. Students who had incomplete questionnaires were excluded. In total, 162 students were recruited to the study.

\section{Instruments}

Critical Thinking Dispositions Inventory-Chinese Version (CTDI-CV) ${ }^{[10]}$ : The CTDI-CV, which was adapted by Peng et al according to Facione's California Critical Thinking Dispositions Inventory (CCTDI) ${ }^{[11]}$, was implemented to measure critical thinking dispositions of nursing students and registered nurses in China. The CTDI-CV is a standardized, 70-item, multiple choice tests that is scored on each of seven categories: truth seeking (10 items), open-mindedness (10 items), analyticity (10 items), systematicity (10 items), critical thinking self-confidence (10 items), inquisitiveness (10 items), and cognitive maturity (10 items). Responses are recorded using a six-point Likert scale ranging from "strongly agree" to "strongly disagree". Higher scores indicate stronger critical thinking dispositions.

Self-Rating Scale of Self-Directed Learning (SRSSDL) ${ }^{[12]: ~ T h e ~ S R S S D L ~ w a s ~ a ~ s e l f-e v a l u a t i o n ~ t o o l ~ o n ~ s e l f-~}$ directed learning. SRSSDL is composed of 60 items articulated in five subscales: Awareness (12 items), Learning strategies (12 items), Learning activities (12 items), Evaluation (12 items), Interpersonal skills (12 items). Responses for each item are rated by using a five-point Likert scale ranging from "always" to "never". High scores show a high level of self-directed learning.

General Self-efficacy Scale (GSE) ${ }^{[13]}$ : The German version of GSE was originally developed by Jerusalem and Schwarzer in 1981, first as a 20 -item version and later as a reduced 10-item version. High reliability, stability, and construct validity of the GSE scale were confirmed in earlier studies ${ }^{[13,14]}$. Responses for each item are rated by using a four-point Likert scale ranging from "completely incorrect" to "complete correct". High scores indicate a high level of self-efficacy.

Demographic questionnaire: A demographic information sheet was used to acquire basic information, such as gender, age, like nursing, learning resources, learning motivation and so on. 


\subsection{Data collection and procedures}

The theoretical and practical course of Surgical Nursing were taught in two semesters. The first semester (2019.09-2020.01) comprising 15 weeks was traditional offline teaching, which was carried out according to teaching plan and syllabus. Due to the COVID-19 outbreak, the second semester comprising 14 weeks (2020.02-2020.05) was online teaching. Students completed a demographic form, CTDI-CV, SRSSDL and GSE scale prior to traditional teaching, and at the end of semester 1 and semester 2.

\section{Curricular Framework for Surgical Nursing online}

The curricular design of Surgical Nursing was based on "Teacher-oriented, Student-centered" education concept. According to the syllabus and teaching objectives, combined with online teaching resources, course team reconstructed online teaching process and progress. Online teaching of Surgical Nursing mainly relied on online platforms such as Tencent Meeting, Tencent Classroom, QQ screen sharing, Massive Online Open Courses (MOOCs), Rain Classroom and Questionnaire Star. Online open courses built by MOOCs, electronic version textbooks of People's Medical Publishing House, databases such as Wanfang data, $\mathrm{CNKI}$, teaching courseware and unit quizzes were main curriculum resources. Implement "upload learning materials before class, self-directed learning before class, play the recorded videos in class, answer students' questions in class and unit quizzes and feedback after class" as online teaching model of Surgical Nursing.

\section{Preparation before class}

1) Teachers: Prior to online course, QQ group of Surgical Nursing was set up. Upload learning materials such as literatures, videos, teaching courseware, website links via QQ group and tasks of each lesson, and sum up students' questions and confused knowledge points of each chapter before class. Based on the feedback from the students, lectures recorded the teaching video with 30 min as supplementary curriculum resource. Case-based learning ( $C B L$ ), team-based learning $(T B L)$ and task-driven learning were applicated in practical lessons. The teaching cases were prepared by the core teacher based on the curricular standards, teaching objectives, and students' prior knowledge level, needs and interests. Prior to practical lessons, lectures uploaded cases, tasks and nursing skill videos via QQ group.

2) Students: This was the phase of self-directed learning. Students were required to give feedback about confused knowledge points three days before class. In practical class, students were divided into groups of $5 \sim 6$ people, then discussing cases in groups with online promotive interaction, holding individually accountable to do their share of the work, and identifying nursing problems of patients in the cases. The team members divided their work according to their individual strengths and clinical cases, such as roleplaying, narration, and collection of difficult knowledge.

\section{In class}

Play video recorded by lectures during class, or take class via screen sharing or live broadcast within $45 \mathrm{~min}$. In the last $30 \mathrm{~min}$ of each lesson, lectures concentrated on answering students' questions and 
errors in homework and tasks, and interacted with students via QQ group or Tencent Meeting. Develop students' critical thinking by analyzing cases, formatting nursing care plan, situation simulation online, recording videos of health education and group discussion in the practical class. Enhance their understanding of surgical nursing skills by describing and decomposing nursing skills steps online, watching nursing skill videos and recording videos of practicing nursing skills. Each group showed their nursing diagnosis, measures and videos within $15 \mathrm{~min}$. After the demonstration, students were asked to comment on advantages and disadvantages of nursing diagnosis and measures, and put forward their opinions about presentation of other groups.

\section{After class}

After class, lectures uploaded unit quizzes of each chapter via Rain Classroom and asked students to write learning notes and draw mind maps of important knowledge points. Students were encouraged to display their learning notes and mind maps in the QQ group.

\section{Evaluation of teaching effectiveness}

The evaluations of teaching effectiveness were adopted formative evaluation, including process evaluation and end-stage evaluation. The process evaluations utilized multiple evaluation methods, including conducting questionnaire survey before the beginning of the course, one month later and at the end of course to assess students' the fundamental condition, self-learning, self-efficacy and critical thinking via Questionnaire Star. Additionally, the students and instructors were interviewed respectively to master their opinions and suggestions on the instructional design, process and effectiveness. The score of tests was accounted for $50 \%$ of the total score. The rest were formative evaluations, which mainly included classroom reports, scenario simulation and nursing rounds.

\section{Data analysis}

The data were shown as the mean \pm standard deviation (SD) and analyzed using SPSS 20.0 software package with chi-square (fisher exact probability), t-test, and one-way analysis of variance (ANOVA). The statistical significance was defined as a difference between groups of $P<0.05$.

\section{Results}

\section{Demographic Characteristics}

A total of 162 students (16 [9.9\%] male and 146 [90.1\%] female) with a mean age of $21.06(\mathrm{SD}=0.91)$ ranging from 19 to 24 years participated in the study (Table 1). Regarding career choice during the COVID-19 pandemic, the proportion of students who chose to be a nurse after graduation were increased compared with baseline. Compared with traditional teaching, learning resources in online teaching were more abundant. During COVID-19 pandemic, 60.5\% students admitted that they had enough learning resources. Furthermore, students got learning resource via search engine $(92.0 \%)$, social media $(90.7 \%)$ and Web portals $(40.7 \%)$ during online course. There was no difference in response to the question "learning motivation" between traditional teaching and online teaching. Regarding learning motivation, $54.9 \%$ students selected "sometimes" and $32.7 \%$ selected "often" during online teaching. 
Table 1

Demographics of students participating in the study $(n=162)$.

\begin{tabular}{|c|c|c|c|}
\hline Variable & Baseline (\%) & Traditional teaching (\%) & Online teaching (\%) \\
\hline \multicolumn{4}{|l|}{ Like nursing } \\
\hline No & $9(5.5)$ & $4(2.5)$ & $5(3.1)$ \\
\hline Unclear & $112(70.0)$ & $103(63.5)$ & $94(58.0)$ \\
\hline Yes & $41(25.3)$ & $55(34.0)$ * & $63(38.9){ }^{\#}$ \\
\hline \multicolumn{4}{|c|}{ Engaged in nursing work after graduate } \\
\hline No & $17(10.5)$ & $4(2.4)$ & $5(3.1)$ \\
\hline Unclear & $54(33.3)$ & $56(34.6)$ & $43(26.5)$ \\
\hline Yes & $91(56.2)$ & $102(63.0)$ * & $114(70.4) \#$ \\
\hline \multicolumn{4}{|c|}{ Learning resources } \\
\hline Never & $1(0.6)$ & $1(0.6)$ & 0 \\
\hline Little & $19(11.7)$ & $15(9.3)$ & $5(3.1)$ \\
\hline Much & $98(60.5)$ & $72(44.4)$ & $59(36.4)$ \\
\hline Very Much & $43(26.5)$ & $73(45.1)$ & $97(59.9)$ \\
\hline Complete & $1(0.6)$ & $1(0.6)$ * & $1(0.6)$ 肍 \\
\hline \multicolumn{4}{|c|}{ Learning motivation } \\
\hline Never & 0 & 0 & 0 \\
\hline Rarely & $27(16.6)$ & 19 (11.7) & 19 (11.7) \\
\hline Sometimes & $94(58.0)$ & $87(53.7)$ & 89 (54.9) \\
\hline Often & 35 (21.6) & $52(32.1)$ & $53(32.7)$ \\
\hline Always & $6(3.7)$ & $4(2.5)$ * & $1(0.6) \#$ \\
\hline
\end{tabular}

\section{Perception and attitude towards online teaching of Surgical Nursing}

As shown in Table 2, although $38.8 \%$ participants held positive attitude towards online teaching of Surgical Nursing, only $9.3 \%$ of them admitted that the effect of online teaching was better than traditional teaching. Regarding what happened to you during online teaching, $89.3 \%$ students admitted that they felt tired of eyes facing screen for a long time, $70.0 \%$ students reported network interruption and excess 
phone data traffic, $63.2 \%$ students acknowledged they were unable to concentrate on learning, and $53.4 \%$ of them admitted they had low efficiency of study. Furthermore, $22.7 \%$ students spent over $6 \mathrm{~h}$ on social media usage per day. Nearly $71.0 \%$ students suggested that each lesson of online teaching should be within $40 \mathrm{~min}$. The most effective ways of online course were watching teaching videos recorded by lecturers (64.8\%), group discussion (21.6\%), online courses (6.8\%) and reading relevant books $(6.8 \%)$. Furthermore, the most effective ways of online practical teaching on surgical nursing skills were watching nursing skills videos (71.0\%), CBL in groups (67.3\%), and describing and decomposing surgical nursing skills step by step by themselves (56.8\%). Meanwhile, $15.4 \%$ participants admitted online teaching was not suitable for practice learning. The most effective ways to finish homework were mind map (35.2\%), self-directed learning (29.6\%) and online quizzes via the Rain Class (29.6\%). 96.3\% students did not agree with taking videos as homework. $51.9 \%$ students acknowledged that the time of each homework would be limited to $30 \mathrm{~min}$. The disadvantages of online teaching were poor learning effectiveness (30.9\%), poor learning atmosphere $(25.9 \%)$ and poor learning surroundings $(22.8 \%)$. 
Table 2

Perception and attitudes towards online teaching of Surgical Nursing

\begin{tabular}{|c|c|}
\hline Variable & $\mathrm{n}(\%)$ \\
\hline \multicolumn{2}{|l|}{ Attitudes towards online teaching } \\
\hline Strongly disagree & $5(3.1)$ \\
\hline Disagree & $21(13.0)$ \\
\hline Not agree & $73(45.1)$ \\
\hline Agree & $49(30.2)$ \\
\hline Strongly agree & $14(8.6)$ \\
\hline \multicolumn{2}{|l|}{ Compared with traditional teaching, the effect of online teaching } \\
\hline Better than traditional teaching & $14(8.6)$ \\
\hline Same effect & $47(29.0)$ \\
\hline Worse than traditional teaching & $101(62.4)$ \\
\hline \multicolumn{2}{|l|}{ The duration of each lesson in online teaching } \\
\hline$<10 \min$ & 0 \\
\hline$<20 \min$ & $4(2.5)$ \\
\hline$<30 \min$ & $43(26.5)$ \\
\hline$<40 \min$ & $115(71.0)$ \\
\hline \multicolumn{2}{|l|}{ The most helpful way to learn in online teaching } \\
\hline Group discussion & $35(21.6)$ \\
\hline Teaching videos recorded by the teachers & $105(64.8)$ \\
\hline Online courses & $11(6.8)$ \\
\hline Reading books & $11(6.8)$ \\
\hline \multicolumn{2}{|l|}{ The most helpful way to learn surgical nursing practical teaching online } \\
\hline Watching nursing skills video & $115(71.0)$ \\
\hline Describing and decomposing surgical nursing skills steps by themselves & $92(56.8)$ \\
\hline Case-based learning in groups & $109(67.3)$ \\
\hline Recording videos in groups & $26(16.0)$ \\
\hline Not ideal online & $25(15.4)$ \\
\hline The most helpful way to finish homework & \\
\hline
\end{tabular}




\begin{tabular}{|ll|}
\hline Variable & $\mathbf{n}(\%)$ \\
\hline Unit quizzes via Rain Classroom & $48(29.6)$ \\
\hline Mind map & $57(35.2)$ \\
\hline Concept map & $3(1.9)$ \\
\hline Recording videos in groups & $6(3.7)$ \\
\hline Self-directed learning & $48(29.6)$ \\
\hline Time spent on each homework & \\
\hline$<20$ min & $28(17.3)$ \\
\hline$<30$ min & $84(51.9)$ \\
\hline$<40$ min & $28(17.3)$ \\
\hline$<50$ min & $4(2.5)$ \\
\hline$<60$ min & $18(11.1)$ \\
\hline The disadvantages of online teaching & \\
\hline Insufficient learning resources & $7(4.3)$ \\
\hline Poor learning surroundings & $37(22.8)$ \\
\hline Poor learning effect & $50(30.9)$ \\
\hline Limited learning approaches & $26(16.0)$ \\
\hline Poor learning atmosphere & $42(25.9)$ \\
\hline
\end{tabular}

\section{Comparison between traditional teaching and online teaching}

As depicted in Table 3, compared with the baseline, there were no significant differences between the mean scores obtained of self-directed learning, critical thinking and self-efficacy after performing online teaching. Of the five subscales in SRSSDL, learning strategies and interpersonal skills were significantly improved after performing online teaching in comparison with baseline (Fig. 1). However, a significant decrease in awareness was observed after online teaching compared with baseline. The comparison of the mean scores obtained for the different dimensions of critical thinking after the implementation of online teaching showed a significant increase in analyticity (Fig. 2). Moreover, there were significant differences between the mean scores obtained for CTDI-CV, SRSSDL and GSE after performing traditional teaching compared with baseline. Differences between the face-to-face and online teaching were found in terms of self-directed learning, critical thinking and self-efficacy. $68.6 \%$ students finished all 13 units quizzes via the Rain Classroom in the semester 1 , and the mean accuracy rate was $0.91 \%(S D=0.05)$. 
During the online teaching, $78.9 \%$ students finished all 12 units quizzes, and the mean accuracy rate was $0.94 \%(S D=0.06)$, which was higher than the traditional teaching (Fig. 3).

Table 3

Outcomes of self-efficacy, self-directed learning and critical thinking between traditional teaching and online teaching.

\begin{tabular}{|c|c|c|c|}
\hline Variable & Baseline & Traditional teaching & Online teaching \\
\hline & $M(S D)$ & $M(S D)$ & $M(S D)$ \\
\hline Self-efficacy & $2.36(0.40)$ & $2.50(0.45)$ * & $2.34(0.44)^{\square}$ \\
\hline Self-directed learning & $207.87(25.71)$ & $216.09(23.40)$ * & $208.81(24.91)^{\square}$ \\
\hline Critical thinking & $216.2(25.36)$ & $227.18(16.63)$ * & $217.96(23.49)^{\square}$ \\
\hline \multicolumn{4}{|c|}{ 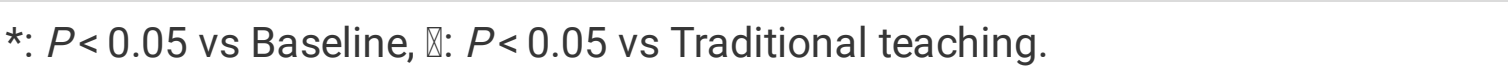 } \\
\hline \multicolumn{4}{|c|}{ *: $P<0.05$ vs Baseline, $\#: P<0.05$ vs Baseline. } \\
\hline
\end{tabular}

\section{Discussion}

In the emerging and ever-changing COVID-19 context, universities should implement a number of measures to slow the virus spread. The safety and health of students and the faculty members should be the top priority. Postponing or cancelling classroom-based class and academic activities are an essential means to protect the health of students and the faculty members. Following the government's requirement of "nonstop teaching and learning", almost all existing course were moved to online in a matter of days. This is an unprepared challenge for millions of faculty members and administrators and tens of million students in colleges and universities that everyone must face. In this study, although $38.8 \%$ students held positive attitudes towards online teaching, only $8.6 \%$ students admitted the effect of online teaching on Surgical Nursing was better than traditional teaching. Evidence has suggested that online learning in undergraduate nursing education is no less effective than traditional means $[15,16]$. Although the advantages of online teaching including enhancing engagement, learning easier in groups, flexibility in time allocated to complete tasks have been reported, it is challenge for impaired communication due to poor network access ${ }^{[17]}$. $70.0 \%$ students experienced network interruption and excess phone data traffic resulting in poor teaching effect. During the COVID-19 pandemic, the majority of faulty members and students had encountered technical difficulties such as poor internet connection and the lack of computer. Therefore, ensure the smooth implementation of teaching activities through combined usage of multiple platforms to avoid problems such as stuck and interruption of teaching activities due to network and large visitor volume. In the online course of Surgical Nursing, lectures used 
various platforms including QQ group, WeChat, Tencent Classroom, Tencent Meeting, Rain Classroom and other apps for online teaching.

In order to ensure the effectiveness of online teaching, well-considered and durable teaching plans as well as emergency prepared plans for unexpected problems were prepared. Therefore, there were various types and quantities of online teaching methods such as live broadcast and online interaction, live broadcast, recording and online interaction, self-directed learning, MOOCs, Small Private Online Courses (SPOC), PPT and online interaction and answering questions online. In this study, $64.8 \%$ students admitted that they were more likely to prefer recording videos of each chapter and answering questions online. Each lesson should be limited within $40 \mathrm{~min}$. Meanwhile, if you normally teach a 3-hour class, summarize its essence in a video no longer than 30 minutes ${ }^{[18]}$. Experts have suggested that lectures should not convert their entire lecture contents to videos because students are not willing to watch slides without a teacher' face or voice ${ }^{[18]}$. Compared with traditional in-class lectures, faculty have less control online teaching, and students are more likely to "skip the class" ${ }^{[3]}$. In order to strengthen learning effectiveness and students' high-level active learning outside of class, faculty members could release homework and reading requirements. In the course of Surgical Nursing, unit quizzes for each chapter via Rain Classroom, mind map for important knowledge points, keep class notes, reading literatures and taking videos were the common manners of homework. The most popular ways of homework were mind map (35.2\%), unit quizzes (29.6\%) and self-directed learning (29.6\%) in this study. However, most students complained about heavy workload leading to poor effectiveness of completion of homework at initial stage of online teaching. 89.3\% students admitted that they felt tired of eyes facing screen for a long time. Hence, each task was best completed within 30 min.

Practical teaching for surgical nursing skills training, as an important part of Surgical Nursing, is difficult to be implemented online. Drainage bag replacement, fracture plaster fixation and closed thoracic drainage were the main practical teaching content in the semester 2. Combined with the current actual situation, teaching plan had been appropriately revised, and training of surgical nursing skills was moved to offline after resuming classes. CBL, TBL and task-driven teaching were applicated in practical lessons online. The most effective ways implemented in practical teaching were watching videos of nursing skills (71.0\%), CBL (67.3\%) and describing and decomposing surgical nursing skills steps by themselves (56.8\%). Evidence has shown that CBL is an effective educational method for developing critical thinking, reinforcing peers' potentials and improving diagnostic abilities ${ }^{[19]}$. Furthermore, the web-based CBL is not inferior to the traditional classroom CBL method ${ }^{[20]}$. It was worth to be noted that students were disgusted with taking videos as assignments. In order to diversity case tasks, the lecture asked students to show simple nursing skill such as shoulder joint movement, or health education by taking videos. However, only $16.0 \%$ students chose to take video clips in this study. Due to the influence of objective factors such as the network coverage of students' area, and different family economy, students in remote villages or poor families cannot got equal education. In addition to great difference in students' personal conditions, heavy workload was also an important factor influencing students' willing to take video clips. 
In general, poor learning effectiveness and poor learning atmosphere were the disadvantages of online courses.

Insufficient pre-class preparation, limited participation in class discussion, and inadequate discussion are common phenomena in online teaching ${ }^{[3]}$. In order to solve such problems in online teaching, expert recommends that faculty should consider two phases of teaching, the offline self-learning phase and the online teaching phase ${ }^{[3]}$. In the present study, the scores of self-directed and self-efficacy were not significantly different. This outcome could possibly be attributed to the fact that students studied at home, which made students more difficult to manage themselves. Especially, the scores of awareness in self-directed learning were decreased. Students were accustomed to lecture in-class and depend on faculty direction leading to low-level active in learning online. Interestingly, the scores of learning strategies and interpersonal skills in self-directed learning were increased compared with baseline. Maybe it is because that students were required to read the course-specific literature and watch various videos in the offline self-learning phase. Meanwhile, during the COVID-19 pandemic, learning resources were more abundant and open than before, and there were more opportunities for group learning.

Critical thinking is an important skill for all nurses, as the ability to critically assess and interpret situations and to use the knowledge correctly will enable them to provide optimal comprehensive care and other services ${ }^{[21]}$. In this study, significant differences in the measure of critical thinking between online course and face-to-face class were observed due to various influencing factors, including learning surroundings, the instructors' approaches to teach, students' intrinsic motivation and learning strategies. However, it was reported that critical thinking is enhanced via online learning ${ }^{[22,23]}$. This inconsistent result may be due to the fact that online teaching as part of blended teaching is well-prepared and technology-support. Among the seven subscales, the scores of truth seeking, maturity, systematicity and inquisitiveness were found to be lower than traditional teaching, suggesting that the students were week in intellectual curiosity and desire for learning, courageous about asking questions, decision-making and using organized and focused methods of reasoning. Nevertheless, the accuracy rate and the proportion of completing all unit quizzes were higher than traditional teaching. Although students actively participated in discussion online and unit quizzes, high-frequency interaction did not achieve the desired outcome and curiosity and desire for learning were still low. The best online instructors set up their courses so that students can pursue self-paced enquiry under their own initiative ${ }^{[18]}$. The progress of online teaching largely depends on students' high-level active learning, which adheres to the educational concept of "Student-centered". Strengthen the learning requirements, enhance the enthusiasm and initiative of self-directed learning are key factors in online teaching. Studying at home was challenge for students' self-management due to lack of learning atmosphere. It was worth to be noted that the mean score of analyticity was higher than traditional learning, indicating that students prized the application of reasoning and the use of evidence to resolve problem.

\section{Conclusion}


The sudden outbreak of COVID-19 accelerates the acceptance of online teaching by all the staff in colleges and universities in China. In this study, most students held neutral attitude towards online teaching in Surgical Nursing. Task-driven learning, recording videos and answering questions online were more suitable for theoretical teaching online. Watching nursing skills video and $\mathrm{CBL}$ in groups were more suitable for practical teaching online. Students were more likely to prefer unit quizzes online and mind maps as homework. Individual students' grades in unit quizzes improved, but there were no differences in student evaluations of instruction mean scores for critical thinking, self-directed learning and selfefficacy. Nearly $3 / 5$ students admitted the effect of online teaching was worse than traditional teaching. In conclusion, face-to-face teaching in classroom and interpersonal interaction in the real situation are insurmountable limitations in online teaching, leading to failure to achieve the expected teaching effectiveness.

\section{Abbreviations}

CBL: Case-based learning; COVID-19: Coronavirus disease 2019; CTDI-CV: Critical Thinking Dispositions Inventory-Chinese Version; GSE: General Self-efficacy Scale; MOOCs: Massive Online Open Courses; PPT: PowerPoint; SARS-CoV-2: Severe acute respiratory syndrome coronavirus 2; SPOC: Small Private Online Courses; SRSSDL: Self-Rating Scale of Self-Directed Learning; TBL: Team-based learning

\section{Declarations}

\section{Acknowledgments}

We thank Hubei University of Chinese Medicine for providing us to conduct this study and its ethical approval.

\section{Authors' contributions}

We thank XZ and TZ designed research; XZ and TZ conducted research; XZ analyzed data; XZ wrote the manuscript; TZ provided language help, and TZ had primary responsibility for the final content. All authors revised it critically for important intellectual content.

\section{Funding}

This work was supported by the National Natural Science Found of China (No. 82003448).

\section{Availability of data and materials}

All the data supporting the study findings are within the manuscript. Additional detailed information and raw data are available from the corresponding author on reasonable request.

\section{Ethical Approval and consent to participate}


Prior to data collection, the protocol was reviewed and ethical permission for the study was received from the Hubei university of Chinese Medicine human ethics committee. All students were informed for All nurses were informed for their voluntary participation and they have the right to refuse, withdraw or stop at any time during their participation. Their identities and potential risks were strictly kept and maintained confidential throughout the study.

\section{Consent for publication}

Not applicable.

\section{Declaration}

The authors declare that they have no competing interests.

\section{Author details}

School of Nursing, Hubei University of Chinese Medicine, Wuhan, China.

${ }^{*}$ Corresponding to: Dr. Zheng Taoyun, Nursing Educator, School of Nursing, Hubei University of Chinese Medicine, Wuhan, China, phone: +86027-688890395. E-mail: 52165460@qq.com

\section{References}

1. World Health Organization. (2020). Coronavirus disease 2019 (COVID-19): situation report, 206. Retrieved from Geneva: https://apps.who.int/iris/handle/10665/333839.

2. Araújo, F.J.O., de Lima, L. S. A., Cidade, P. I. M., et al. Impact Of Sars-Cov-2 And Its Reverberation In Global Higher Education And Mental Health. Psychiatry Res, 2020. 288: p. 112977.

3. Bao, W. COVID-19 and online teaching in higher education: A case study of Peking University. Hum Behav Emerg Technol, 2020. 2(2): p. 113-115.

4. Ferrel, M. N. and Ryan, J. J. The Impact of COVID-19 on Medical Education. Cureus, 2020. 12(3): p. e7492.

5. Sinclair, P., Kable, A., and Levett-Jones, T. The effectiveness of internet-based e-learning on clinician behavior and patient outcomes: a systematic review protocol. JBI Database System Rev Implement Rep, 2015. 13(1): p. 52-64.

6. Brusamento, S., Kyaw, B. M., Whiting, P., Li, L., et al. Digital Health Professions Education in the Field of Pediatrics: Systematic Review and Meta-Analysis by the Digital Health Education Collaboration. J Med Internet Res, 2019. 21(9): p. e14231.

7. Milic, N.M., Trajkovic, G. Z., Bukumiric, Z. M., et al. Improving Education in Medical Statistics: Implementing a Blended Learning Model in the Existing Curriculum. PLoS One, 2016. 11(2): p. e0148882. 
8. Munro, V., Morello, A., Oster, C., et al. E-learning for self-management support: introducing blended learning for graduate students - a cohort study. BMC Med Educ, 2018. 18(1): p. 219.

9. Ozturk, E., van lersel, M., van Loon, K., et al. Interactive online learning on perioperative management of elderly patients. Am J Surg, 2018. 216(3): p. 624-629.

10. Peng, M.C., Wang, G.C., Chen, J.L., et al. (2004). Validity and reliability of the Chinese critical thinking disposition inventory. J Nurs in China (Zhong Hua Hu Li Za Zhi), 39, 644-647.11.

11. Facione, N.C., Facione, P. A and Sanchez, C.A.G. Critical Thinking Disposition as a Measure of Competent Clinical Judgment: The Development of the California Critical Thinking Disposition Inventory. J Nurs Educ, 1994. 33(8): p. 345-350.

12. Williamson, S.N., Development of a self-rating scale of self-directed learning. Nurse Res, 2007. 14(2): 66-83.

13. Cheung, S. K. and Sun, S.Y. Assessment of optimistic self-beliefs: further validation of the Chinese version of the General Self-Efficacy Scale. Psychol Repo, 1999. 85(3_suppl): p. 1221-1224.

14. Luszczynska, A., Scholz, U., Schwarzer, R. The general self-efficacy scale: multicultural validation studies. J Psychol, 2005. 139(5): p. 439-457.

15. McCutcheon, K., Lohan, M., Traynor, M., et al. A systematic review evaluating the impact of online or blended learning vs. face-to-face learning of clinical skills in undergraduate nurse education. J Adv Nurs, 2015. 71(2): p. 255-70.

16. Pei, L. Wu, H. Does online learning work better than offline learning in undergraduate medical education? A systematic review and meta-analysis. Med Educ Online, 2019. 24(1): p. 1666538.

17. Willemse, J.J., Jooste, K., Bozalek, V. Experiences of undergraduate nursing students on an authentic mobile learning enactment at a higher education institution in South Africa. Nurse Educ Today, 2019. 74: p. 69-75.

18. Gewin, V. Five tips for moving teaching online as COVID-19 takes hold. Nature, 2020. 580(7802): p. 295-296.

19. Gholami, M., Saki, M., Toulabi, T., et al. Iranian Nursing Students' Experiences of Case-Based Learning: A Qualitative Study. J Prof Nurs, 2017. 33(3): p. 241-249.

20. Chan, A.W., Chair, S. Y., Sit, J. W. Case-Based Web Learning Versus Face-to-Face Learning: A MixedMethod Study on University Nursing Students. J Nurs Res, 2016. 24(1): p. 31-40.

21. Yu, D., Zhang, Y., Xu, Y., et al. Improvement in Critical Thinking Dispositions of Undergraduate Nursing Students Through Problem-Based Learning: A Crossover-Experimental Study. J Nurs Educ, 2013. 52(10): p. 574-581.

22. Brahler, C.J., Quitadamo, I.J., Johnson, E.C. Student critical thinking is enhanced by developing exercise prescriptions using online learning modules. Adv Physiol Educ, 2002. 26(1-4): p. 210-21.

23. Novotny, N.L., Stapleton, S.J. and Hardy, E.C. Enhancing Critical Thinking in Graduate Nursing Online Asynchronous Discussions. J Nurs Educ, 2016. 55(9): p. 514-21. 
Figures

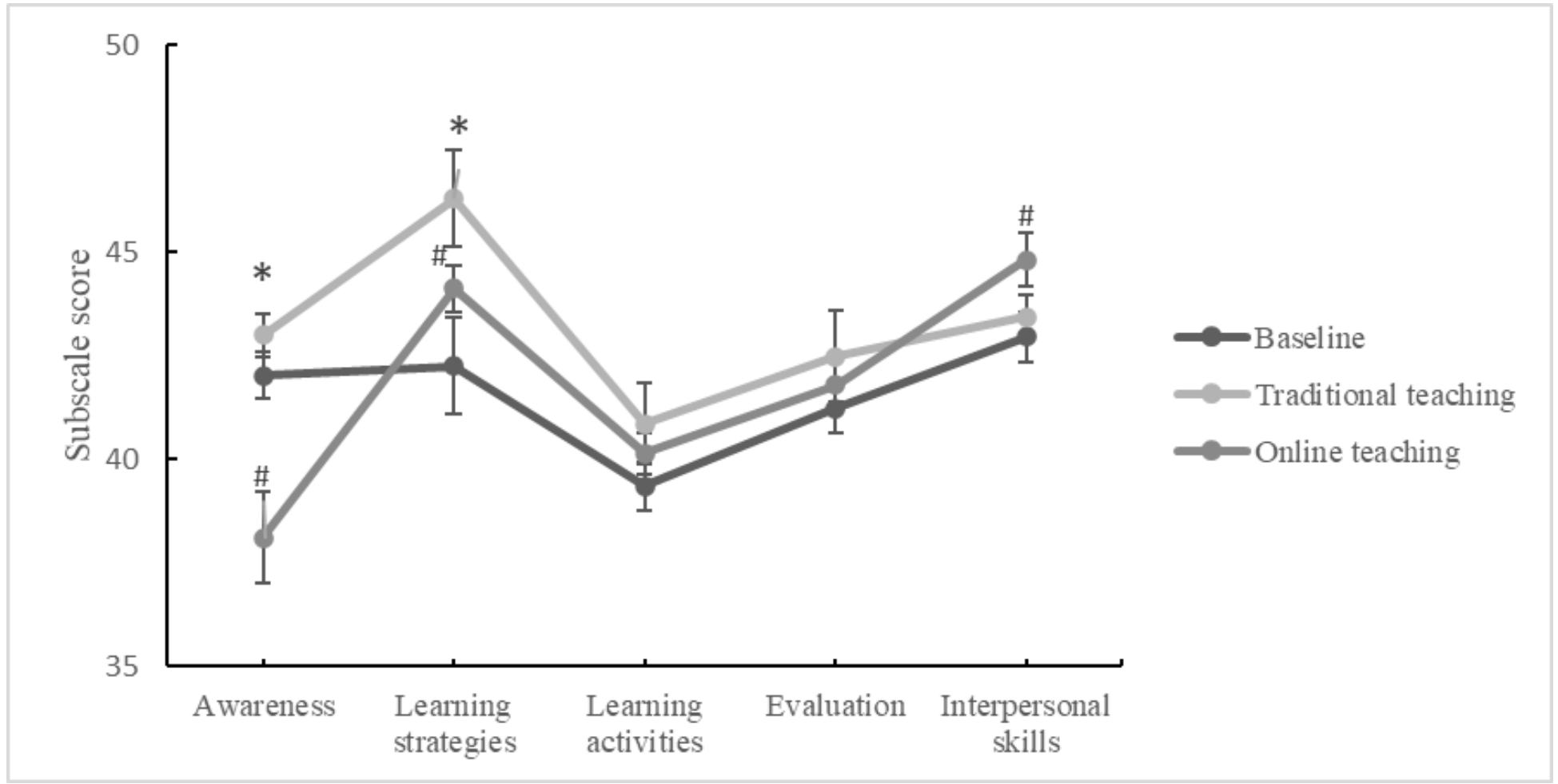

\section{Figure 1}

Outcomes of subscales in self-directed learning between traditional teaching and online teaching. *: $P<0.05$ vs Baseline, \#: $P<0.05$ vs Baseline.

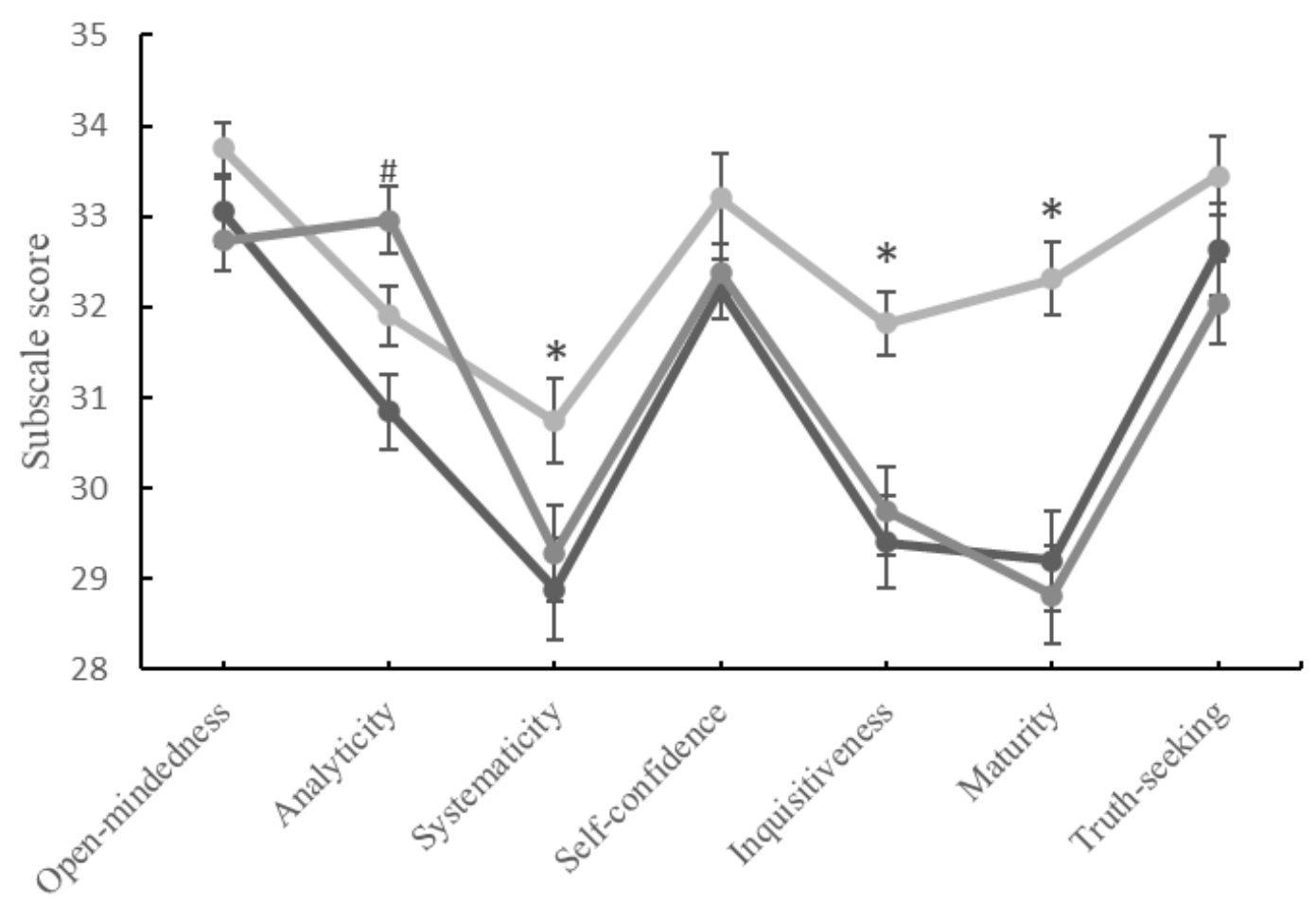

Baseline

- Traditional teaching Online teaching 
Figure 2

Outcomes of subscales in critical thinking between traditional teaching and online teaching. *: $P<0.05$ vs Baseline, \#: $P<0.05$ vs Baseline.

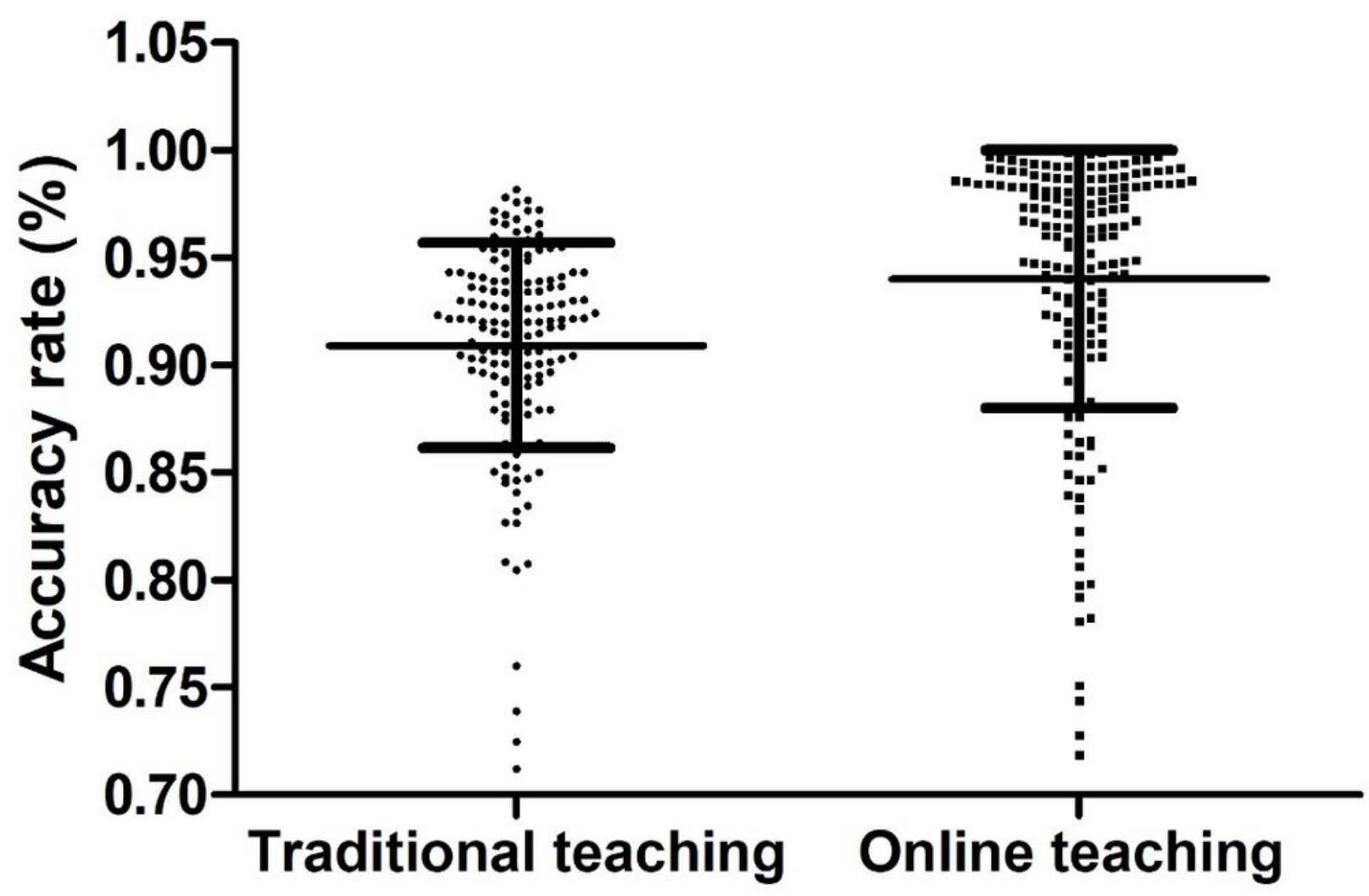

Figure 3

Outcomes of regular unit quizzes between traditional teaching and online teaching.

\section{Supplementary Files}

This is a list of supplementary files associated with this preprint. Click to download.

- questionnaire.docx 